\title{
Lithium protects dopaminergic cells from rotenone toxicity via autophagy enhancement
}

\author{
Lingling Hou ${ }^{1 \dagger}$, Nian Xiong ${ }^{2 \dagger}$, Ling $\mathrm{Liu}^{2 \dagger}$, Jinsha Huang ${ }^{2}$, Chao Han², Guoxin Zhang ${ }^{2}$, Jie Li ${ }^{2}$ Xiaoyun Xu², \\ Zhicheng Lin ${ }^{3}$ and Tao Wang ${ }^{2^{*}}$
}

\begin{abstract}
Background: Previous studies have indicated that enhancement of autophagy lysosome pathway may be beneficial for Parkinson's disease (PD), in which aberrant accumulation of aggregated/misfolded proteins and mitochondrial dysfunction are considered as crucial pathogenesis. Recently, a number of studies have suggested the neuroprotective effects of lithium in models of several neurodegenerative diseases including PD. However, the exact mechanisms underlying this neuroprotection remain unclear. In our study, rotenone-exposed SH-SY5Y cells were used as an in vitro parkinsonian model to assess the autophagy-enhancing effect of lithium and the underlying mechanisms were further investigated.

Results: Similar to the common used autophagy enhancer rapamycin (Rap, $0.2 \mu \mathrm{M}$ ), lithium (LiCl, $10 \mathrm{mM}$ ) significantly recovered the shrinkage of SH-SY5Y cells, and alleviated rotenone-induced cell apoptosis, mitochondrial membrane potential reduction and reactive oxygen species accumulation. Furthermore, the protective effects induced by LiCl were partially blocked by the co-treatment of autophagy inhibitors such as 3-methyladenine (3-MA, $10 \mathrm{mM}$ ) or chloroquine (CHL, $10 \mu \mathrm{M})$. Moreover, 3-MA or Chl suppressed LiCl-induced autophagy in the immunoblot assay. In addition, the co-localization of LC3 and mitochondria and the preservation of mitochondrial function within LiCl-treated cells were observed, confirming that the damaged mitochondria were cleared through autophagy (mitophagy).
\end{abstract}

Conclusions: These findings suggested that lithium exerted neuroprotection against rotenone-induced injuries partially through the autophagy pathway. Pharmacologically induction of autophagy by lithium may represent a novel therapeutic strategy as a disease-modifier in PD.

Keywords: Lithium, Autophagy, SH-SY5Y Cells, Parkinson's disease

\section{Background}

Parkinson's disease (PD), a chronic and progressive neurodegenerative disease, is manifested as motor symptoms such as tremor, bradykinesia, rigidity and postural instability, as well as non-motor symptoms such as depression, apathy, sleep disorders and erectile dysfunction [1]. The hallmark pathological signs of PD include the

\footnotetext{
*Correspondence: wangtaowh@hust.edu.cn

${ }^{\dagger}$ Lingling Hou, Nian Xiong and Ling Liu contributed equally to this work

2 Department of Neurology, Tongji Medical College, Union Hospital,

Huazhong University of Science and Technology, Wuhan, Hubei, China

Full list of author information is available at the end of the article
}

degeneration of dopaminergic (DA) neurons in the substantia nigra and the formation of $\alpha$-synuclein + protein aggregates which are called Lewy bodies or Lewy neurites in the remaining DA neurons. Although treatments that slow or halt the disease process are currently unavailable, manipulating protein aggregation seems to have great potential for disease-modification [1].

There are two important mechanisms for protein degradation in the mammal cells, detailed as the autophagylysosome pathway (ALP) and the ubiquitin-proteasome system (UPS). Previous studies have demonstrated that dysfunction of these two systems plays vital roles in 
the pathogenesis of PD [2-5]. The function of UPS is limited by the core volume, and upregulated proteasome activity only leads to non-selective degradation of key short-lived intracellular regulators, resulting in detrimental consequences, such as cancer in the case of tumor suppressor p53 [1]. In contrast, ALP degrades entire organelles such as mitochondria and large membrane proteins which fail to recycle by UPS $[4,6]$. Thus, enhancement of autophagy might be a novel strategy for the treatment of protein accumulation-related diseases, such as PD.

The commonly used strategy for inducing autophagy is employing rapamycin, an inhibitor of the mammalian target of rapamycin (mTOR) $[7,8]$. Previous studies have revealed that rapamycin exerts neuroprotective effects in several models of neurodegenerative diseases such as Alzheimer's disease (AD) and PD through autophagy enhancement [9-11]. However, since mTOR plays an important role in regulating a variety of basic cellular processes, long-term use of rapamycin may cause some deleterious consequences, including cell over-growth and proliferation [12]. It is crucial to explore an autophagy enhancer which is safe, clinical-relevant and easy to administrate.

Unlike rapamycin, lithium ( $\mathrm{LiCl}$ ) induces autophagy via an mTOR-independent pathway. By inhibiting the inositol monophosphatase (IMPase), $\mathrm{LiCl}$ ultimately results in the reduction of free inositol cellular level [13-16]. A recent study has indicated that $\mathrm{LiCl}$ suppressed $A \beta$ pathology by inhibiting the translation of protein in a Drosophila model of AD [17]. Furthermore, $\mathrm{LiCl}$ protected against paraquat-induced neurotoxicity by NRF2 activation and miR-34a inhibition in SH-SY5Y cells [18]. Moreover, our previous studies have suggested that $\mathrm{LiCl}$ might be neuroprotective in rotenone-induced SH-SY5Y cells and MPTP-lesioned mice though autophagy enhancement $[19,20]$. However, another study have indicated that $\mathrm{LiCl}$ was unable to alleviate the degeneration of DA neurons induced by 6-OHDA, suggesting that GSK3 was minimally involved in the neurodegeneration [21]. Thus, it remains unclear whether or not $\mathrm{LiCl}$ exerts neuroprotective effects and by which pathway $\mathrm{LiCl}$ is involved in the neuroprotection.

In this study, rotenone-exposed SH-SY5Y cells were used as an in vitro model of PD, and cell viability, activation of apoptosis, oxidative stress and mitochondrial dysfunction were assessed respectively [3, 22, 23, 24]. Rapamycin was used as a positive control for induction of autophagy. The neuroprotective effects of $\mathrm{LiCl}$ on the rotenone-induced cellular model as well as the underlying mechanisms were further explored.

\section{Results}

\section{$\mathrm{LiCl}$ increased cell viability upon rotenone exposure} in SH-SY5Y cells

We first examined whether or not $\mathrm{LiCl}$ affected cell survival under normal culture condition. MTT analysis indicated that in the range of $1 \mathrm{mM}$ to $15 \mathrm{mM}, \mathrm{LiCl}$ did not significantly affect the viability of SH-SY5Y cells, while the concentration of $50 \mathrm{mM} \mathrm{LiCl}$ directly caused $48.3 \pm 5.37 \%$ reduction of MTT absorbance. When treated with rotenone for $24 \mathrm{~h}$, rotenone decreased cell viability by $67.56 \%$ compared with control group, and by $37.46,32.61,18.32,13.68,23.94$ and $41.21 \%$ in $\mathrm{LiCl} 2+$ Rot, $\mathrm{LiCl} 4$ + Rot, $\mathrm{LiCl} 8$ + Rot, LiCl10 + Rot, $\mathrm{LiCl} 15+$ Rot and LiCl50 + Rot groups, respectively (Fig. 1b). LiCl with a dose range from $2 \mathrm{mM}$ to $50 \mathrm{mM}$ could alleviate rotenone-induced cell death. Moreover, the most significant cytoprotection of $\mathrm{LiCl}$ was observed at the concentration of $10 \mathrm{mM}$ (Fig. 1b). Therefore, we chose the concentration of $10 \mathrm{mM}$ for the subsequent tests.

\section{LiCl prevented from rotenone-induced cell injury}

First, LiCl-induced neuroprotection was revealed by cell morphology. SH-SY5Y cells under normal culture condition grew into a neuron-like phenotype with extended neuritis. Exposure to rotenone $(200 \mathrm{nM})$ for $24 \mathrm{~h}$ resulted in shortening of neurites and shrinking of the cell bodies, which was inhibited by rapamycin or $\mathrm{LiCl}$ pretreatment (Fig. 2a). However, the rehabilitative effect of $\mathrm{LiCl}$ was partially blocked when cells were co-treatment with the autophagy inhibitors 3-MA or CHL. The MTT assay indicated that rotenone significantly decreased cell viability by $\sim 60 \%$, while pretreatment with rapamycin or $\mathrm{LiCl}$ significantly attenuated the toxic effects induced by rotenone. (Figure $2 \mathrm{~b}$ ). Such rescue of cell viability was partially attenuated by simultaneously pretreatment of 3-MA or CHL. Similar results were observed from cell apoptosis analysis (Fig. 3a). Rotenone exposure led to an increase of cell apoptosis, which was discounted by $\mathrm{LiCl}$ or rapamycin pretreatment, while the protective effect of $\mathrm{LiCl}$ was partially weakened by $3-\mathrm{MA}$ or $\mathrm{CHL}$, suggesting that the neuroprotective effect of $\mathrm{LiCl}$ may be related to autophagy induction (Fig. 3a).

\section{$\mathrm{LiCl}$ protected against rotenone-induced mitochondrial dysfunction}

The SH-SY5Y cells in negative control showed accumulation of red fluorescence and extended neurites, while rotenone exposure led to reduced red fluorescence with condensed nuclei and cell shrinkage, indicating a collapse of MMP with exposure to rotenone (Fig. 3c). The reduction in MMP meant a lower capacity to produce ATP. 

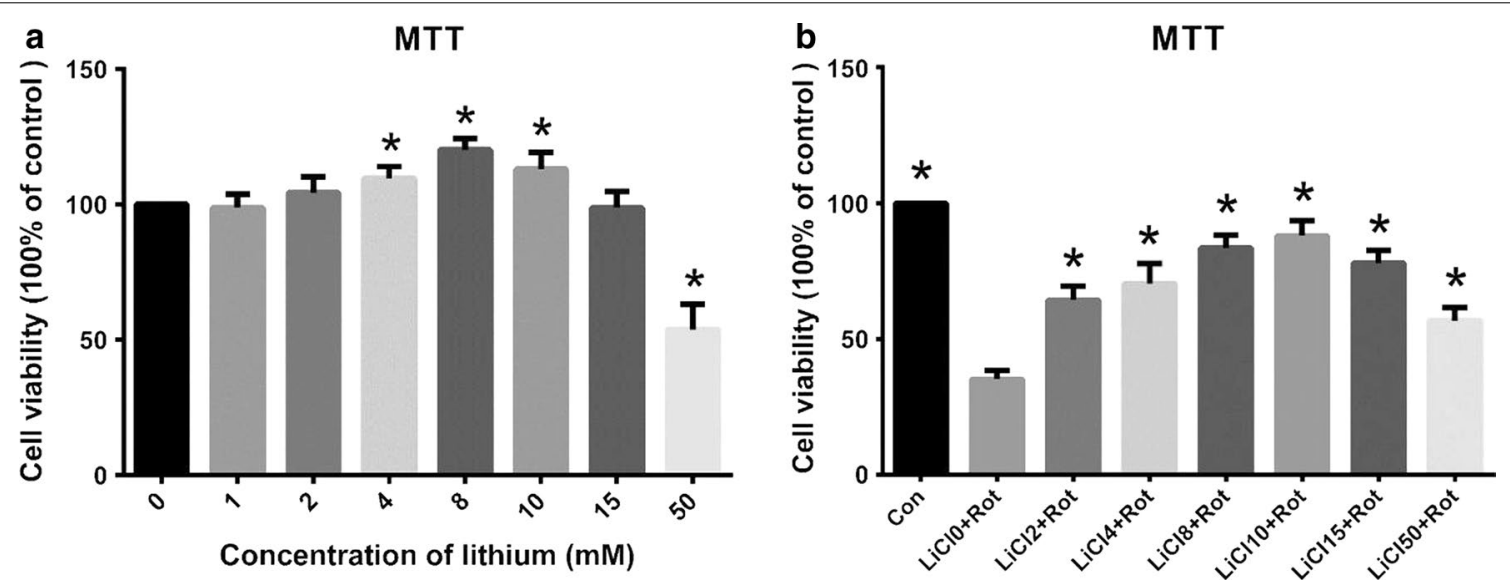

Fig. 1 Lithium protected against rotenone-induced cytotoxicity in SH-SY5Y cells. Cell viability was measured by MTT assay after treatment of SHSY5Y cells with lithium for $24 \mathrm{~h}$ at indicated concentrations with or without rotenone exposure. a Lithium exposure (0-15 mM) had no negative influence on the cell survival of SH-SY5Y cells under normal culture condition. b Lithium dose-dependently protected SH-SY5Y cells from rotenoneinduced cytotoxicity. ${ }^{*} P<0.05$ as compared with control (a) or LiCl $0+$ Rot-treated cells $(\mathbf{b})(n=6$ in each group)

Then the cells pretreated with $\mathrm{LiCl}$ significantly inhibited the decrease of fluorescence intensity, indicating that $\mathrm{LiCl}$ prevented rotenone-induced mitochondrial injury. In one hand, mitochondrial dysfunction triggered ROS formation, on the other hand, accumulated ROS could in turn cause oxidative damage of mitochondria. To confirm the neuroprotective effect of $\mathrm{LiCl}$ on mitochondria, we measured the levels of ROS in different groups. Rotenone evoked obvious production of ROS, and $\mathrm{LiCl}$ indeed alleviated the overgeneration of ROS. However, this protective effect of $\mathrm{LiCl}$ was partially attenuated when cells were simultaneously pretreated with 3-MA or CHL (Fig. 3b). In addition, pretreatment of cells with $\mathrm{CHL}$ resulted in a higher level of ROS release than the rotenone group, indicating that $\mathrm{CHL}$ increased cellular vulnerability to rotenone toxicity and mitochondrial dysfunction.

\section{LiCl enhanced autophagy in SH-SY5Y cells}

In immunoblot assay, the ratio of LC3-II/I with $\mathrm{LiCl}$ pretreatment was increased by $\sim 84 \%$ when compared to the vehicle control, similar tendency to that of the rapamycin, while the ratio was slightly decreased with co-treatment of $\mathrm{LiCl}$ and 3-MA. LC3 expression was highest in the group with co-treatment of $\mathrm{LiCl}$ and $\mathrm{CHL}$. By disrupting the $\mathrm{pH}$ of acidic vesicles, $\mathrm{CHL}$ prevented the fusion process of lysosomes and autophagosomes, and ultimately elevated the cellular burden of autophagosome accumulation [25]. Thus, the accumulation of LC3-II, a classic marker of autophagosome, suggested either that autophagy has been stimulated and/or that the maturation of autophagosomes has been blocked (in the case of the addition of CHL) [26]. Our immunoblot assay indicated that autophagy was up-regulated during $\mathrm{LiCl}$ or rapamycin exposure, and such induction of autophagy was attenuated when cells were treated with 3-MA or CHL simultaneously (Fig. 4), suggesting that the protective effect of $\mathrm{LiCl}$ was related to the induction of autophagy.

\section{Damaged mitochondria were eliminated via autophagy}

To detect the association between autophagy induction and the restored mitochondrial function, further immunostaining analysis without rotenone exposure was performed. The results showed that $\mathrm{LiCl}$ treatment contributed to a punctuate pattern of LC3 fluorescence in the cytoplasm of SH-SY5Y cells, while it led to a diffuse distribution of LC3 in the absence of LiCl. Additionally, this effect could be partially attenuated by 3-MA or CHL co-treatment (Fig. 5). As shown in the Fig. 5r, there is no statistical difference between these groups regarding the normalized MitoTracker Red fluorescence in the cytoplasm. However, 3-MA or CHL co-treatment significantly reduced the $\mathrm{LC} 3$ aggregation induced by $\mathrm{LiCl}$ (Fig. 5q). Co-localization of MitoTracker Red and LC3 indicated that the turnover of mitochondria might be within autophagolysosomes.

\section{Discussion}

As a mood stabilizer, $\mathrm{LiCl}$ is traditionally used to treat bipolar disorder [27]. Recent research has focused on its neuroprotective potential and regarded it as a candidate agent for disease-modifying therapy in several neurodegenerative diseases [28-30]. The neuroprotective effect of $\mathrm{LiCl}$ may rely on autophagy induction. In our study, human SH-SY5Y cells exposed to rotenone were used 

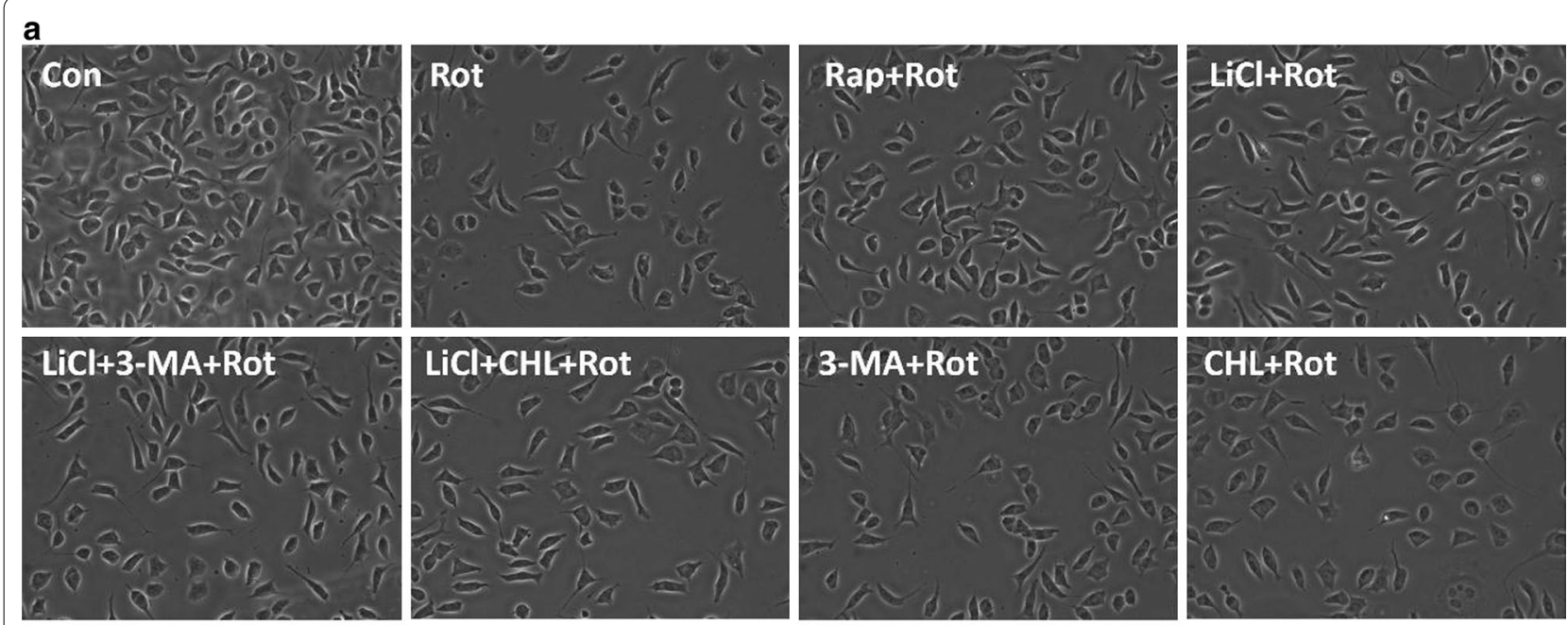

b

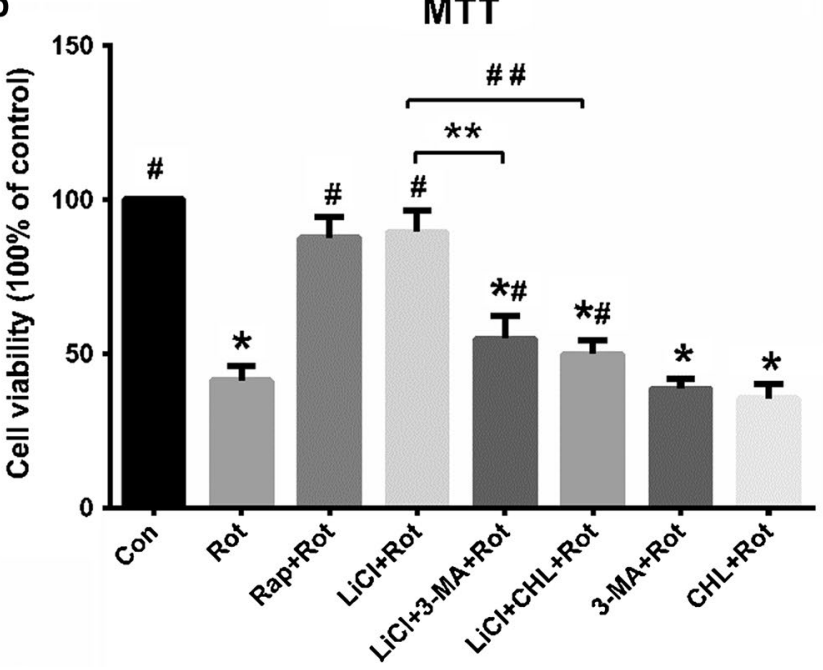

Fig. 2 Co-treatment with autophagy inhibitors attenuated neuroprotection of lithium and increased vulnerability of SH-SY5Y to rotenone. Cells were pretreated with autophagy-related drugs for $24 \mathrm{~h}$ followed by rotenone exposure for another $24 \mathrm{~h}$. The morphology changes of cells were shown in (a). The cell viability was measured by MTT assay (b) or Annexin-V/PI staining by flow cytometry (Fig. 3a). ${ }^{*} P<0.05$ versus control; ${ }^{\#} P<0.05$ versus rot alone; ${ }^{*} P<0.05$ as compared with $\mathrm{LiCl}+$ Rot group; ${ }^{\#} P<0.05$ as compared with $\mathrm{LiCl}+$ Rot group ( $n=6$ in each group)

as an in vitro model of PD to explore the effects of $\mathrm{LiCl}$ on rotenone neurotoxicity and its underlying mechanisms. These findings indicated that $\mathrm{LiCl}$ could attenuate cell apoptosis, inhibit ROS production and MMP decrease induced by rotenone. Moreover, the protective effects were partially blocked upon pretreatment with autophagy inhibitors such as 3-MA or CHL.

Compared with control group, the ratio of LC3II/I was elevated by $\mathrm{LiCl}$ treatment, showing that $\mathrm{LiCl}$ induced autophagy in SH-SY5Y cells. However, this autophagy-enhancing effect was partially blocked by 3-MA, a widely used inhibitor of autophagy. As CHL could enhance the cellular burden of autophagosomes which were manifested as the accumulation of LC3-II protein, the increased ratio of LC3-II/I by chloroquine treatment indicated that the maturation of autophagosomes has been blocked, representing an inhibition of the autophagy flux [25].

As a mitochondrial complex I inhibitor, rotenone is extensively used for modelling PD in recent years. In this study, rotenone induced mitochondrial dysfunction as evidenced by the increased production of ROS and the decreased MMP, which may lead to the activation of the mitochondrial apoptotic pathway [31-33]. Mitochondria have been proposed as an important link among risk factors, and eliminating injured mitochondria would be 


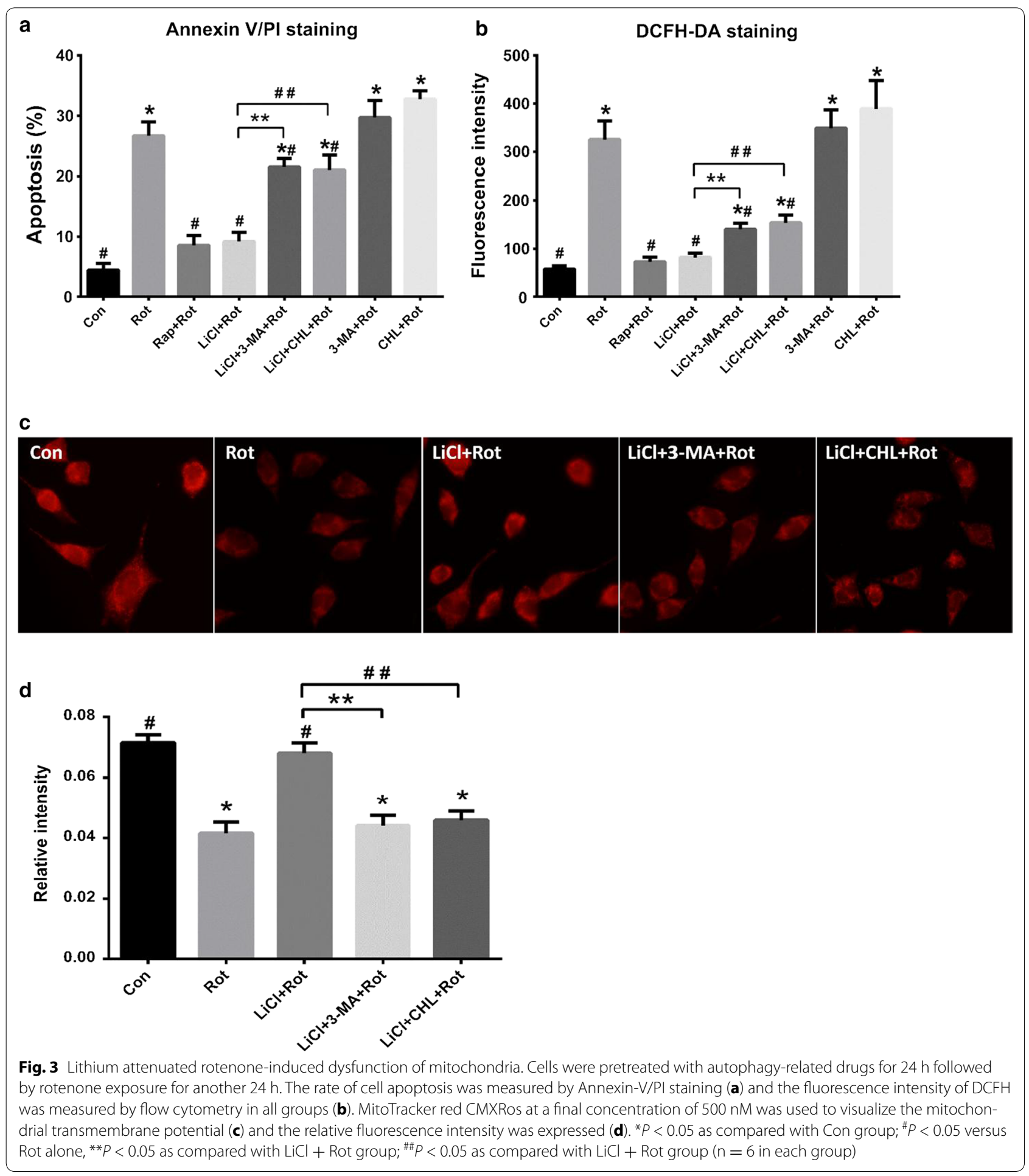

critical to prevent cells from a series of pro-apoptotic cellular responses. Autophagy is the only process by which organelles such as mitochondria can be degraded. Previous studies indicated that inhibited autophagy was accompanied by accumulated mitochondrial mass
[34-36]. Thus, we hypothesized that pretreatment with autophagy-enhancing agents like $\mathrm{LiCl}$ might be able to reduce mitochondrial load. As expected, $\mathrm{LiCl}$ reduced rotenone-induced apoptosis, ROS production and MMP reduction, exerting similar neuroprotective 


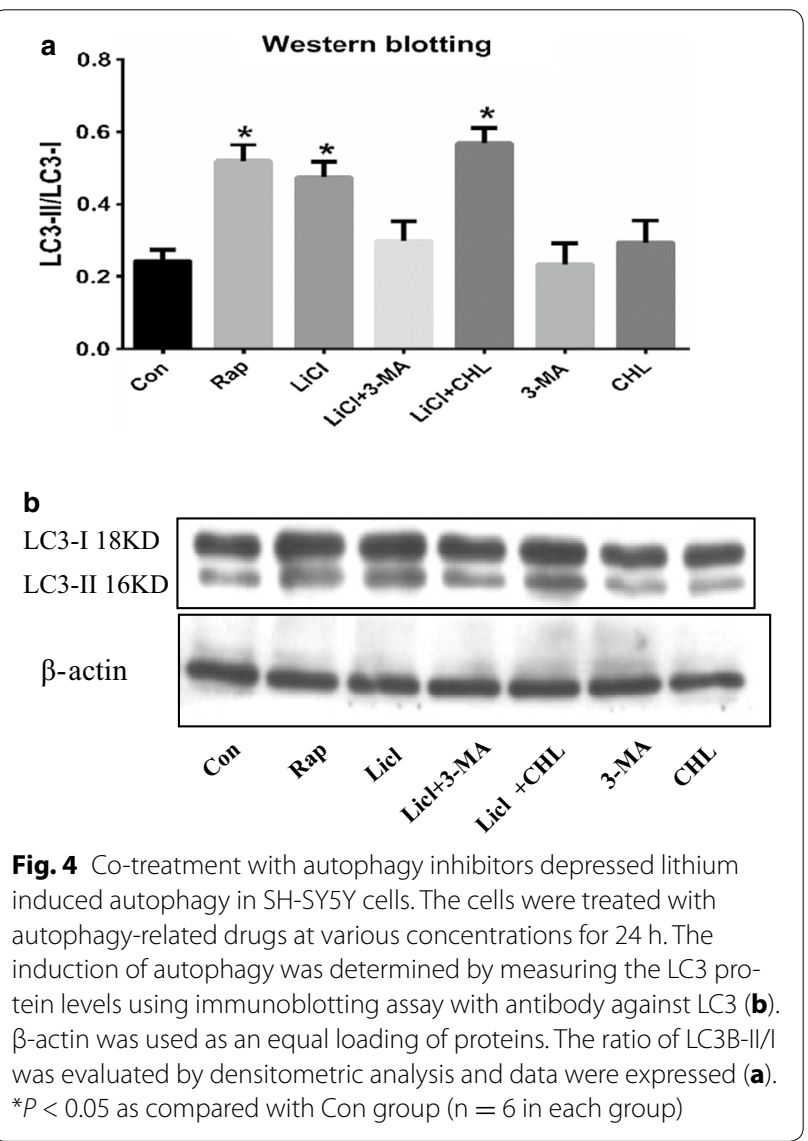

effects to another autophagy enhancer rapamycin. To further investigate whether the neuroprotection of $\mathrm{LiCl}$ was autophagy-dependent, two chemical suppressors of autophagy 3-MA and CHL were used. The converse results were observed in cells treated simultaneously with 3-MA or CHL, corresponding to the reduced ratio of LC3II/I which suggested that the protective effect of $\mathrm{LiCl}$ could be partially blocked as autophagy was inhibited. Then we observed that the mitochondria fluorescence was well merged with the LC3 fluorescence in the cytoplasm of LiCl-treated cells when compared to those treated with autophagy inhibitors or vehicle control. This further supported an elimination of mitochondria via autophagy. As the sole known mechanism for mitochondrial turnover, autophagy serves to preserve the balance between organelle biogenesis and their clearance, and engages in cross-talk with mitochondria and oxidative stress [37].

Our study have indicated that $\mathrm{LiCl}$ alleviated rotenoneinduced cell apoptosis and ROS production through autophagy induction, which was consistent with previous findings that induction of autophagy could protect against pro-apoptotic insults by reducing mitochondrial load [16, 38, 39]. Scola et al. also found that lithium prevented rotenone-induced changes in mitochondrial complex I function, cell death and changes to DNA methylation and hydroxymethylation [39]. These findings let us have a more balanced view on the effects of lithium. Since lithium is known to pass the blood-brain barrier and has already been approved by FDA for decades for the treatment of bipolar disorder [40], we could reasonably speculate that by inducing autophagy, lithium may have great potential as a novel therapy for PD, although the possibility requires further investigation.

\section{Conclusions}

Taken together, these findings indicated that lithium was able to attenuate cell apoptosis, inhibit ROS production and MMP decrease induced by rotenone in SH-SY5Y. Moreover, autophagy enhancement was involved in this neuroprotection as the effects of lithium were partially blocked upon pretreatment with autophagy inhibitors. Pharmacologically induction of autophagy by lithium may raise a new hope for novel disease-modifying strategies in PD.

\section{Methods}

\section{Cell culture and treatment}

Human neuroblastoma SH-SY5Y cells (ATCC, Manassas, VA, USA) were cultured in DMEM/F12 medium (Invitrogen, Carlsbad, CA, USA) at $37{ }^{\circ} \mathrm{C}$ with $5 \% \mathrm{CO}_{2}$ and $95 \%$ air $(\mathrm{v} / \mathrm{v})$. The growth medium was supplemented with $10 \%$ fetal bovine serum (Invitrogen). Rotenone (Sigma-Aldrich, St. Louis, MO, USA) and rapamycin (Sigma-Aldrich) were dissolved in dimethyl sulfoxide (DMSO) before diluted with the culture medium, and the final concentration of DMSO per well was less than $0.2 \%$. 3-methyladenine (3-MA) (Sigma-Aldrich) was dissolved by heating in $\mathrm{ddH}_{2} \mathrm{O}$, while $\mathrm{LiCl}$ and chloroquine $(\mathrm{CHL})$ were dissolved in phosphate buffered solution (PBS) before dilution with the culture medium. PBS and DMSO were added to the culture medium in negative control group (PBS for $24 \mathrm{~h}$ following DMSO for another $24 \mathrm{~h}$, "Con-group"). The final concentrations of Rap [20, 41], $\mathrm{LiCl}[20,42], 3-\mathrm{MA}$ and $\mathrm{Chl}[20,43]$ were $0.2 \mu \mathrm{M}, 1-50 \mathrm{mM}, 10 \mathrm{mM}$ and $10 \mu \mathrm{M}$, respectively. Rotenone $(200 \mathrm{nM})$ was given for $24 \mathrm{~h}$ to induce cell damage. For MTT assay, apoptosis analysis, mitochondrial membrane potential (MMP) and reactive oxygen species (ROS) detection, SH-SY5Y cells were pretreated with vehicle (PBS), Rap, $\mathrm{LiCl}, \mathrm{LiCl}+3-\mathrm{MA}, \mathrm{LiCl}+\mathrm{CHL}$, 3-MA, CHL, respectively, for $24 \mathrm{~h}$, and then rotenone for another $24 \mathrm{~h}$. For assessing microtubule associated protein 1 light chain 3 (LC3) expression in immunostaining and immunoblotting, the cells were only treated with vehicle, $\mathrm{Rap}, \mathrm{LiCl}, \mathrm{LiCl}+3-\mathrm{MA}, \mathrm{LiCl}+\mathrm{CHL}, 3-\mathrm{MA}$, $\mathrm{CHL}$, respectively, for $24 \mathrm{~h}$. 


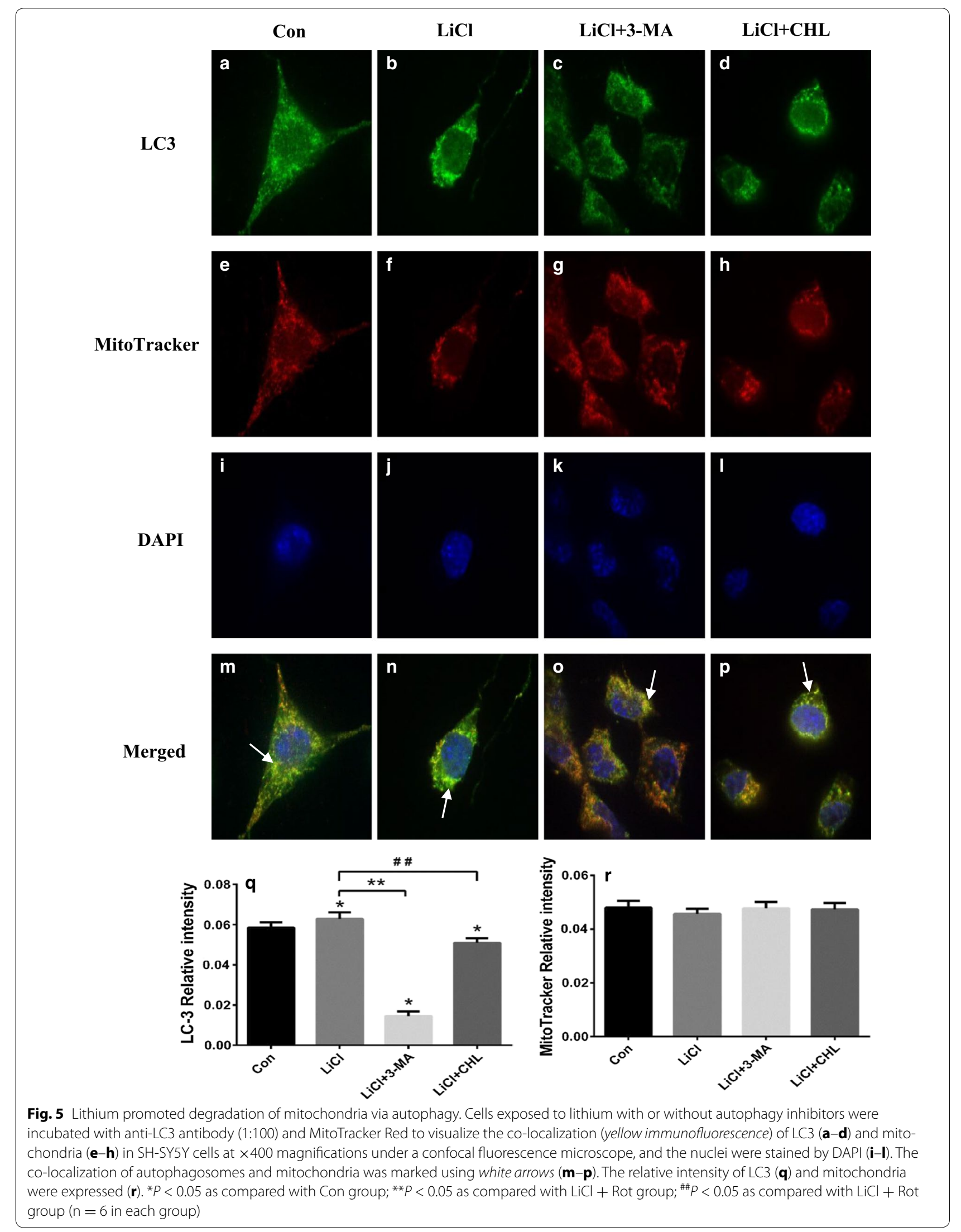




\section{Measurement of cell viability}

Cell viability was detected in MTT assay by a microplate reader (Bio-Rad, Hercules, CA, USA) [22, 44, 45]. Briefly, SH-SY5Y cells were seeded at a density of $1 \times 10^{4}$ cells per well in 96-well plates. When exposed to different treatments for the indicated times duration, $20 \mu \mathrm{L}$ of MTT solution ( $5 \mathrm{mg} / \mathrm{mL}$, Sigma-Aldrich) were added to each well for $4 \mathrm{~h}$ to allow the formation of purple formazan crystal. Then, $100 \mu \mathrm{L}$ of the solubilization reagent was added into each well and spectrophotometrically measured for absorption at $\lambda 570 \mathrm{~nm}$.

\section{Apoptosis analysis}

The FITC-conjugated Annexin V (Annexin V, SigmaAldrich) and propidium iodide (PI, Sigma-Aldrich) double-staining followed by flow cytometry (BD, Franklin Lakes, NJ, USA) assessment was employed to analyze the rates of cell apoptosis [22, 44, 45]. Cultivated termination, $2 \times 10^{6}$ cells were harvested with $0.25 \%$ trypsin and washed with PBS, and then incubated with Annexin V-FITC (apoptosis detection kit, Sigma-Aldrich) and $20 \mu \mathrm{g} / \mathrm{mL}$ PI $(10 \mu \mathrm{L})$ for $10 \mathrm{~min}$ at $37^{\circ} \mathrm{C}$ in the darkness. Then FITC and PI signals were measured with a BD-LSR flow cytometer using the CellQuest software. Data were analyzed by FSC express version 3.0 (De Novo Software, Los Angeles, CA, USA). The apoptosis rate $=[$ Annexin $\mathrm{V}(+) \mathrm{PI}(-)$ cells + Annexin $\mathrm{V}(+) \mathrm{PI}(+)$ cells]/total cell $\times 100 \%$.

\section{Measurement of reactive oxygen species}

Fluorescent probe 2,7-dichlorofluorescein diacetate $\left(\mathrm{H}_{2}\right.$ DCFDA $)$ was used to measure the intracellular ROS $[22,44,45]$. The generation of dichlorofluorescein (DCF), an oxidized form of $\mathrm{H}_{2} \mathrm{DCFDA}$, is proportional to intracellular ROS levels. At the termination of medication, cells were harvested, resuspended in PBS and immediately incubated with $10 \mu \mathrm{M} \mathrm{H}_{2}$ DCFDA (Sigma-Aldrich) for $30 \mathrm{~min}$ at $37^{\circ} \mathrm{C}$ in the darkness. After washed, the samples were detected by a FACScan flow Cytometer (BD). Data were analyzed by FSC express version 3.0 (De Novo Software, Los Angeles, CA, USA).

\section{Detection of mitochondrial membrane potential}

Since MitoTracker probe could pass through the plasma membrane and accumulate in mitochondria [22, 46], assessment of MMP was performed using MitoTracker Red CMXRos (Invitrogen). After harvested and resuspended with PBS, cells were cultured with MitoTracker Red CMXRos (500 nM) for $30 \mathrm{~min}$ at $37{ }^{\circ} \mathrm{C}$ in the darkness, washed with PBS twice and then the nuclei were stained with DAPI (Invitrogen). The MMP level was visualized quantitatively as red fluorescence, while the DNA could be simultaneously observed as blue fluorescence.

\section{Autophagy detection in immunoblotting analysis}

Autophagy level was detected by a specific marker protein, the autophagosomal membrane form of microtubule-associated protein 1 light chain 3 (LC3) [5], which has two forms, LC3-I (18 KD, a cytoplasmic form) and LC3-II (16 KD, a cleavage form). The conversion of LC3-I into LC3-II (LC3-II level compared to LC3-I level) was indicative of autophagic activity. Higher ratio of LC3II/LC3-I means higher autophagic activity. After harvested and washed by cold PBS, cells were directly lysed in $100 \mathrm{~mL}$ of $2 \times$ SDS sample buffer containing protease inhibitors and boiled for $5 \mathrm{~min}[22,44,45]$. Then total protein concentration was determined by a BCA kit (Pierce, Rockford, IL, USA). Equal amounts of proteins $(40 \mathrm{mg})$ were separated by SDS-polyacrylamide gel electrophoresis and transferred to polyvinylidene difluoride membrane (Pierce). The membranes were then washed three times with PBS, blocked with $5 \%$ dry milk in Tris-buffered saline for $45 \mathrm{~min}$ and incubated with primary antibodies directed against LC3 (1: 1000) and $\beta$-actin (Santa Cruz, Santa Cruz, CA, USA) overnight at $4{ }^{\circ} \mathrm{C}$. Following three 10-min washes in tris-buffered saline tween-20, the membranes were incubated with the corresponding secondary antibody conjugated with HRP at room temperature for $1 \mathrm{~h}$. Antibody binding was visualized using enhanced chemiluminescence ECL-Plus (Amersham Pharmacia, Piscataway, NJ, USA). Blots were quantified using analysis system (Quantity One, Hercules, CA, USA).

\section{Visualization of the autophagic degradation of mitochondria (mitophagy)}

When harvested, SH-SY5Y cells were fixed with $4 \%$ paraformaldehyde (Amresco llc, Solon, OH, USA) at $4{ }^{\circ} \mathrm{C}$ for 10 min, washed with PBS and permeabilized with $0.5 \%$ Triton X-100 for $2 \mathrm{~min}$, then incubated with primary antibody, the monoclonal anti-LC3 antibody (1:100) overnight at $4{ }^{\circ} \mathrm{C}$ followed by the secondary antibody, a fluorescein isothiocyanate conjugated goat anti-rabbit antibody (1:60, Sigma-Aldrich) for $2 \mathrm{~h}$ at room temperature. Cells were observed by using a confocal microscope (Olympus, Tokyo, Japan) and then images were analyzed by Image-Pro Plus 6.0 software package (Bethesda, MD, USA) [20].

\section{Statistical analysis}

Statistical analyses were carried out using SPSS version 20.0 for Windows (IBM Corporation, New York, USA). All values were expressed as mean $\pm \operatorname{SD}(n=6$ in each group). The statistical significance of differences between groups was evaluated using a one-way ANOVA followed by Fisher's least significant difference $\mathrm{t}$ test, as a normal distribution in all groups was given. $P$ value of $<0.05$ was considered as statistically significant. 


\section{Availability of supporting data}

The data set supporting the results of this article is included within the article.

\begin{abstract}
Abbreviations
ALP: autophagy lysosome pathway; ROS: reactive oxygen species; $\mathrm{CHL}$ : chloroquine; 3-MA: methyladenine; DA: dopaminergic; UPS: ubiquitin-proteasome system; mTOR: mammalian target of rapamycin; IMPase: inositol monophosphatase; Rot: rotenone; MMP: mitochondrial membrane potential; DMSO: dimethyl sulfoxide; PBS: phosphate buffered solution; $\mathrm{H}_{2}$ DCFDA: 2,7-dichlorofluorescein diacetate; DCF: dichlorofluorescein; LC3: microtubule associated protein 1 light chain 3
\end{abstract}

\section{Authors' contributions}

$\mathrm{LH}$ and $\mathrm{JH}$ performed the immunostaining analysis and Western blotting and drafted the manuscript. CH, GZ and XX performed the MTT assay and Flow cytometry manipulations. JL was involved in collecting data. NX and LL designed the study and undertook the statistical analysis. LL and ZL contributed to manuscript revision. The corresponding author TW supervised the whole study. All authors read and approved the final manuscript

\section{Author details}

${ }^{1}$ Department of Emergency, Central Hospital of Wuhan, Wuhan, Hubei, China. 2 Department of Neurology, Tongji Medical College, Union Hospital, Huazhong University of Science and Technology, Wuhan, Hubei, China. ${ }^{3}$ Division of Alcohol and Drug Abuse, Department of Psychiatry and Harvard NeuroDiscovery Center, Harvard Medical School and Laboratory of Psychiatric Neurogenomics, McLean Hospital, Belmont, MA, USA.

\section{Acknowledgements}

This work was supported by Grants 31171211 and 81471305 from the National Natural Science Foundation of China (to TW), Grant 2013BAI09B03 from National Key Technology Research and Development Program of the Ministry of Science and Technology of China (to XS), Grant 81200983 from the National Natural Science Foundation of China (to NX), Grant 81301082 from the National Natural Science Foundation of China (to JSH), Grant 2012 B09 from China Medical Foundation (to NX) and Grant 0203201343 from Hubei Molecular Imaging Key Laboratory (to NX).

\section{Compliance with ethical guidelines}

The experiments described in this paper were approved by the Ethical Committee on Animal Experimentation of Tongji Medical College, Huazhong University of Science and Technology.

\section{Competing interests}

The authors declare that they have no competing interests.

Received: 1 August 2015 Accepted: 18 November 2015 Published online: 25 November 2015

\section{References}

1. Olanow CW, Stern MB, Sethi K. The scientific and clinical basis for the treatment of Parkinson disease (2009). Neurology. 2009;72(21 Suppl 4):S1-136.

2. Pan T, Kondo S, Le W, Jankovic J. The role of autophagy-lysosome pathway in neurodegeneration associated with Parkinson's disease. Brain J Neurol. 2008;131(Pt 8):1969-78.

3. Shen YF, Tang Y, Zhang XJ, Huang KX, Le WD. Adaptive changes in autophagy after UPS impairment in Parkinson's disease. Acta Pharmaco Sin. 2013;34(5):667-73.

4. Xiong N, Xiong J, Jia M, Liu L, Zhang X, Chen Z, Huang J, Zhang Z, Hou L, Luo $Z$, et al. The role of autophagy in Parkinson's disease: rotenone-based modeling. Behav Brain Funct BBF. 2013;9:13.

5. Zheng Q, Li J, Wang X. Interplay between the ubiquitin-proteasome system and autophagy in proteinopathies. Int J Physiol Pathophysio Pharmacol. 2009;1(2):127-42.
6. Mizushima N, Levine B, Cuervo AM, Klionsky DJ. Autophagy fights disease through cellular self-digestion. Nature. 2008:451(7182):1069-75.

7. Cheng Y, Ren X, Hait WN, Yang JM. Therapeutic targeting of autophagy in disease: biology and pharmacology. Pharmacol Rev. 2013;65(4):1162-97.

8. Klionsky DJ, Abdalla FC, Abeliovich H, Abraham RT, Acevedo-Arozena A, Adeli K, Agholme L, Agnello M, Agostinis P, Aguirre-Ghiso JA, et al. Guidelines for the use and interpretation of assays for monitoring autophagy. Autophagy. 2012;8(4):445-544.

9. Cai Z, Zhao B, Li K, Zhang L, Li C, Quazi SH, Tan Y. Mammalian target of rapamycin: a valid therapeutic target through the autophagy pathway for Alzheimer's disease? J Neurosci Res. 2012;90(6):1105-18.

10. Pan T, Kondo S, Zhu W, Xie W, Jankovic J, Le W. Neuroprotection of rapamycin in lactacystin-induced neurodegeneration via autophagy enhancement. Neurobiol Dis. 2008;32(1):16-25.

11. Pan T, Rawal P, Wu Y, Xie W, Jankovic J, Le W. Rapamycin protects against rotenone-induced apoptosis through autophagy induction. Neuroscience. 2009;164(2):541-51.

12. Sarbassov DD, Ali SM, Sabatini DM. Growing roles for the mTOR pathway. Curr Opin Cell Biol. 2005;17(6):596-603.

13. Motoi Y, Shimada K, Ishiguro K, Hattori N. Lithium and autophagy. ACS Chem Neurosci. 2014;5(6):434-42.

14. Sarkar S, Floto RA, Berger Z, Imarisio S, Cordenier A, Pasco M, Cook $\mathrm{LJ}$, Rubinsztein DC. Lithium induces autophagy by inhibiting inositol monophosphatase. J Cell Biol. 2005;170(7):1101-11.

15. Sarkar S, Krishna G, Imarisio S, Saiki S, O'Kane CJ, Rubinsztein DC. A rational mechanism for combination treatment of Huntington's disease using lithium and rapamycin. Hum Mol Genet. 2008;17(2):170-8.

16. Sarkar S, Rubinsztein DC. Inositol and IP3 levels regulate autophagy: biology and therapeutic speculations. Autophagy. 2006;2(2):132-4.

17. Sofola-Adesakin O, Castillo-Quan Jl, Rallis C, Tain LS, Bjedov I, Rogers I, Li L, Martinez P, Khericha M, Cabecinha M, et al. Lithium suppresses Abeta pathology by inhibiting translation in an adult Drosophila model of Alzheimer's disease. Front Aging Neurosci. 2014:6:190.

18. Alural B, Ozerdem A, Allmer J, Genc K, Genc S. Lithium protects against paraquat neurotoxicity by NRF2 activation and miR-34a inhibition in SHSY5Y cells. Front Cell Neurosci. 2015;9:209.

19. Li XZ, Chen XP, Zhao K, Bai LM, Zhang H, Zhou XP. Therapeutic effects of valproate combined with lithium carbonate on MPTP-induced parkinsonism in mice: possible mediation through enhanced autophagy. Int J Neurosci. 2013:123(2):73-9.

20. Xiong N, Jia M, Chen C, Xiong J, Zhang Z, Huang J, Hou L, Yang H, Cao $X$, Liang $Z$, et al. Potential autophagy enhancers attenuate rotenoneinduced toxicity in SH-SY5Y. Neuroscience. 2011;199:292-302.

21. Yong Y, Ding H, Fan Z, Luo J, Ke ZJ. Lithium fails to protect dopaminergic neurons in the 6-OHDA model of Parkinson's disease. Neurochem Res. 2011;36(3):367-74.

22. Xiong N, Huang J, Chen C, Zhao Y, Zhang Z, Jia M, Hou L, Yang H, Cao X, Liang Z, et al. Dl-3-n-butylphthalide, a natural antioxidant, protects dopamine neurons in rotenone models for Parkinson's disease. Neurobiol Aging. 2012;33(8):1777-91

23. Xiong N, Huang J, Zhang Z, Xiong J, Liu X, Jia M, Wang F, Chen C, Cao X, Liang $Z$, et al. Stereotaxical infusion of rotenone: a reliable rodent model for Parkinson's disease. PLoS One. 2009:4(11):e7878.

24. Xiong N, Long X, Xiong J, Jia M, Chen C, Huang J, Ghoorah D, Kong X, Lin Z, Wang T. Mitochondrial complex I inhibitor rotenone-induced toxicity and its potential mechanisms in Parkinson's disease models. Crit Rev Toxicol. 2012;42(7):613-32

25. Yoon YH, Cho KS, Hwang JJ, Lee SJ, Choi JA, Koh JY. Induction of lysosomal dilatation, arrested autophagy, and cell death by chloroquine in cultured ARPE-19 cells. Invest Ophthalmol Vis Sci. 2010;51(11):6030-7.

26. Holt SV, Wyspianska B, Randall KJ, James D, Foster JR, Wilkinson RW. The development of an immunohistochemical method to detect the autophagy-associated protein LC3-II in human tumor xenografts. Toxicol Pathol. 2011:39(3):516-23.

27. D'Souza R, Rajji TK, Mulsant BH, Pollock BG. Use of lithium in the treatment of bipolar disorder in late-life. Curr Psychiatry Rep. 2011;13(6):488-92.

28. Chiu CT, Chuang DM. Neuroprotective action of lithium in disorders of the central nervous system. J Cent South Univ Med Sci. 2011;36(6):461-76. 
29. Pasquali L, Longone P, Isidoro C, Ruggieri S, Paparelli A, Fornai F. Autophagy, lithium, and amyotrophic lateral sclerosis. Muscle Nerve. 2009;40(2):173-94.

30. Wada A, Yokoo H, Yanagita T, Kobayashi H. Lithium: potential therapeutics against acute brain injuries and chronic neurodegenerative diseases. J Pharmacol Sci. 2005;99(4):307-21.

31. Andreyev AY, Kushnareva YE, Starkov AA. Mitochondrial metabolism of reactive oxygen species. Biochem Biokhimiia. 2005;70(2):200-14.

32. Lemasters JJ. Selective mitochondrial autophagy, or mitophagy, as a targeted defense against oxidative stress, mitochondrial dysfunction, and aging. Rejuvenation Res. 2005;8(1):3-5.

33. Perier C, Bove J, Vila M, Przedborski S. The rotenone model of Parkinson's disease. Trends Neurosci. 2003;26(7):345-6.

34. Ganguli A, Choudhury D, Datta S, Bhattacharya S, Chakrabarti G. Inhibition of autophagy by chloroquine potentiates synergistically anti-cancer property of artemisinin by promoting ROS dependent apoptosis. Biochimie. 2014;107 Pt B:338-49.

35. Giordano S, Darley-Usmar V, Zhang J. Autophagy as an essential cellular antioxidant pathway in neurodegenerative disease. Redox Biol. 2014;2:82-90

36. Sato M, Sato K. Degradation of paternal mitochondria by fertilization-triggered autophagy in C. elegans embryos. Science. 2011;334(6059):1141-4.

37. Lee J, Giordano S, Zhang J. Autophagy, mitochondria and oxidative stress: cross-talk and redox signalling. Biochem J. 2012;441(2):523-40.

38. Erlich S, Alexandrovich A, Shohami E, Pinkas-Kramarski R. Rapamycin is a neuroprotective treatment for traumatic brain injury. Neurobiol Dis. 2007;26(1):86-93.
39. Scola G, Kim HK, Young LT, Salvador M, Andreazza AC. Lithium reduces the effects of rotenone-induced complex I dysfunction on DNA methylation and hydroxymethylation in rat cortical primary neurons. Psychopharmacology (Berl). 2014;231(21):4189-98.

40. Manji HK, Lenox RH. Lithium: a molecular transducer of mood-stabilization in the treatment of bipolar disorder. Neuropsychopharmacol Off Publ Am Coll Neuropsychopharmacol. 1998;19(3):161-6.

41. Sarkar S, Davies JE, Huang Z, Tunnacliffe A, Rubinsztein DC. Trehalose, a novel mTOR-independent autophagy enhancer, accelerates the clearance of mutant huntingtin and alpha-synuclein. J Biol Chem. 2007;282(8):5641-52.

42. Williams RS, Cheng L, Mudge AW, Harwood AJ. A common mechanism of action for three mood-stabilizing drugs. Nature. 2002;417(6886):292-5.

43. Zhang JY, Peng C, Shi H, Wang S, Wang Q, Wang JZ. Inhibition of autophagy causes tau proteolysis by activating calpain in rat brain. J Alzheimers Dis. 2009;16(1):39-47.

44. Zhang Z, Cao X, Xiong N, Wang H, Huang J, Sun S, Liang Z, Wang T. DNA polymerase-beta is required for 1-methyl-4-phenylpyridiniuminduced apoptotic death in neurons. Apoptosis Int J Program Cell Death. 2010;15(1):105-15.

45. Ma R, Xiong N, Huang C, Tang Q, Hu B, Xiang J, Li G. Erythropoietin protects PC12 cells from beta-amyloid(25-35)-induced apoptosis via PI3 K Akt signaling pathway. Neuropharmacology. 2009;56(6-7):1027-34.

46. Poot $M$, Zhang $Y Z$, Kramer JA, Wells KS, Jones LJ, Hanzel DK, Lugade AG, Singer VL, Haugland RP. Analysis of mitochondrial morphology and function with novel fixable fluorescent stains. J Histochem Cytochem Off J Histochem Soc. 1996;44(12):1363-72.

\section{Submit your next manuscript to BioMed Central and we will help you at every step:}

- We accept pre-submission inquiries

- Our selector tool helps you to find the most relevant journal

- We provide round the clock customer support

- Convenient online submission

- Thorough peer review

- Inclusion in PubMed and all major indexing services

- Maximum visibility for your research

Submit your manuscript at www.biomedcentral.com/submit
() Biomed Central 